\title{
Peneguhan diagnosa scabiosis metode sitologi kulit pada kucing domestik di Kota Malang
}

\author{
Dodik Prasetyo, Indah Amalia Amri*, Sri Murwani, Dahliatul Qosimah \\ Fakultas Kedokteran Hewan, Universitas Brawijaya, Kota Malang, Jawa Timur
}

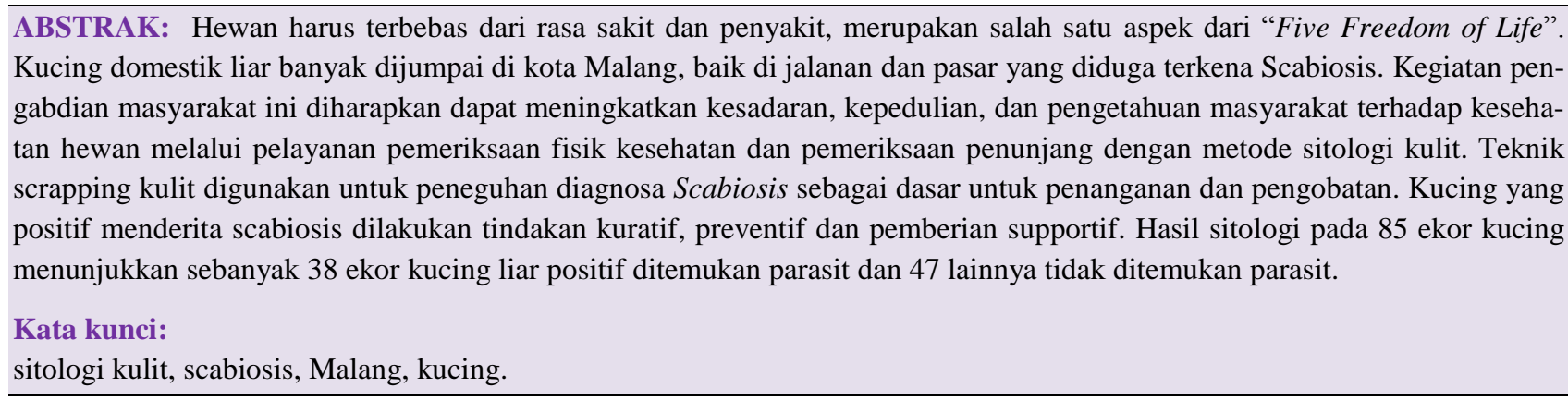

\section{- PENDAHULUAN}

Scabiosis adalah penyakit kulit yang disebabkan oleh tungau dari Family Sarcoptidae antara lain Sarcoptes scabiei dan Notoedress cati (Arlian, 1989). Prevalensi penyakit scabies di dunia cukup tinggi dan merupakan salah satu masalah kesehatan global pada negara berkembang, penyakit ini banyak ditemukan pada tempat yang padat akan memudahkan transmisi penularan tungau dan tidak terjaga kebersihannya serta menyerang pada segala umur (Walton \& Currie, 2007).

Semakin banyaknya masyarakat yang memiliki kepedulian untuk mengadopsi kucing domestik lokal yang tidak terurus di jalanan untuk dipelihara di rumah, menyebabkan maraknya bermunculan komunitas-komunitas pecinta hewan di masyarakat Indonesia. Kota Malang khususnya, terdapat beberapa komunitas pecinta hewan yang dipungut dari jalanan, seperti PKDI (Pecinta Kucing Domestik Indonesia), MCL (Malang Cat Lover), dan Stray Cat Defender (Penyelamat Kucing Jalanan). Semakin banyaknya komunitas pecinta hewan yang menjadikan hewan dari jalanan menjadi hewan peliharaan di kota Malang hendaknya diikuti oleh kesadaran pemilik hewan terhadap kesehatan hewan peliharaanya. Menjaga kesehatan hewan peliharaan antara lain dapat dilakukan dengan secara rutin memeriksakan kesehatan hewan peliharaan ke dokter hewan terdekat.

Kegiatan pemeriksaan dan penanganan pengobatan Scabiosis pada kucing domestik lokal di Kota Malang dengan peneguhan diagnosa metode sitologi kulit merupakan salah satu kegiatan pengabdian masyarakat yang diselenggarakan dengan tujuan untuk memberikan edukasi kepada masyarakat agar lebih peduli terhadap kesehatan hewan peliharaan.

\section{- MATERI DAN METODE}

Pengabdian masyarakat ini dilakukan di Klinik Hewan Pendidikan Fakultas Kedokteran Hewan Universitas Brawijaya yang berlokasi di Jl. M.T Haryono 169 Kota Malang Jawa Timur dan untuk mengefektifkan pelaksanaan pemeriksaan pengobatan juga dilakukan di Shelter Stray Cat Defender di Lowokwaru kota Malang dimana terdapat kucing yang di-rescue dari jalanan yang telah dikumpulkan dan dilakukan pemeriksaan fisik secara umum.

Diagnosa yang dilakukan untuk mengetahui kasus scabiosis adalah dengan cara anamnesa, pemeriksaan gejala klinis dan metode sitologi yaitu teknik scraping. Pemeriksaan klinis meliputi adanya perubahan fisik pada kucing yaitu krusta, papula, vesikula dan alopesia dikarenakan adanya infestasi dari parasit scabies serta adanya hiperkeratosis. Teknik scraping dilakukan dengancara kerokan kulit diambil diarea sekitar lesi, hasil kerokan diletakkan pada objek glass dan ditetesi $\mathrm{KOH} 10 \%$, kemudian diamati diawah mikroskop untuk menemuka ntungau (Malik et al., 2006).

Pelayanan konsultasi kepada pemilik hewan mengenai status kesehatan hewannya juga dilakukan bersamaan dengan kegiatan pengabdian masyarakat ini. Pemilik hewan diharapkan memperoleh pengetahuan mengenai pemeliharaan kesehatan hewan yang tepat setelah konsultasi.

Diterima: 26-02-2019 | Direvisi: 31-03-2019 | Disetujui: 09-04-2019

(C) 2019 CC-BY-SA. Ini adalah artikel Open Access yang didistribusikan berdasarkan ketentuan dari Creative Commons Attribution ShareAlike 4.0 International License (https://creativecommons.org/licenses/by-sa/4.0/). 
- HASIL DAN PEMBAAHASAN

Berdasarkan hasil sitologi sebanyak 85 ekor kucing telah dilakukan pemeriksaan dan pengobatan scabiosis (hasil sitologi 38 ekor positif scabiosis dan 47 lainnya tidak ditemukan scabiosis sebagaimana disajikan pada Gambar 1 .

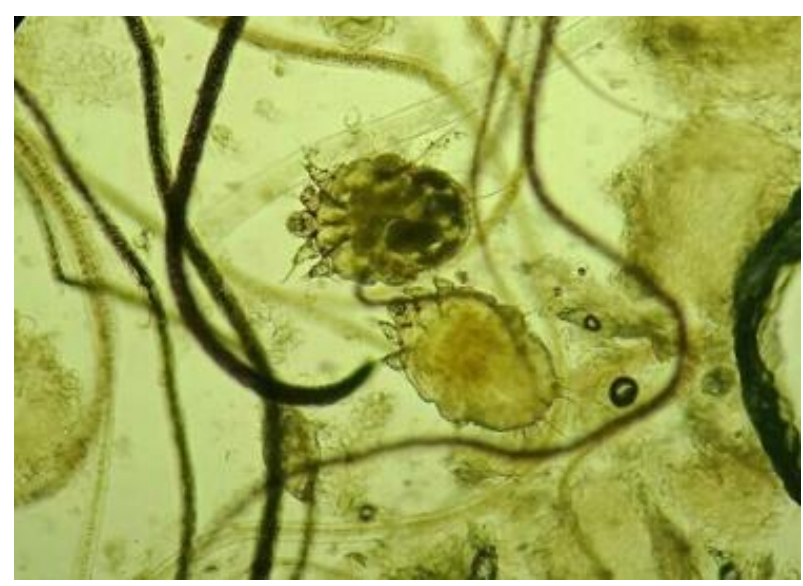

Gambar 1 Hasil pemeriksaan sitologi dengan teknik scrapping (Sarcoptes sbabiei) pada kucing.

Kucing seluruhnya kemudian diberikan selamectin sebagai obat topikal yang efektif membunuh ektoparasit dewasa, mengobati dan mengontrol parasit tungau pada kucing. Selamectin bekerja dengan cara menghambat kerja glutame gated channels pada parasit. Hanya 38 ekor kucing yang didapat tungau scabiosis disarankan untuk dilakukan pemberian ulang selamectin setiap 2 minggu dengan 3 kali ulangan bergantung keparahan scabiosis yang berlangsung pada tubuh kucing (Ghubash, 2006). Pemberian salep antibiotik dan antihistamin juga dilakukan pada kucing yang memiliki indikasi luka disertai infeksi bakteri, dan antihistamin diberikan untuk mengurangi rasa gatal.

Terdapat metode lain yang digunakan untuk mendiagnosa scabiosis yaitu menggunakan burrow ink test (tes tinta terowongan), pemberian tinta cina dilakukan pada kulit yang terinfeksi, dan ditutup selama 20-30 menit. Hasil positif scabies berupa gambaran khas berupa warna tinta dalam jaringan berbentuk zig - zig (Amanda et al., 2018). Berdasarkan penelitian Amanda 2018, metode burrow ink test memiliki kesesuaian baik dengan metode scraping kulit.

Pada kegiatan ini dilakukan penyuluhan mengenai pemeliharaan kucing yang baik dan benar, terdapat beberapa tindakan preventif scabiosis antara lain: 1) rutin membersihkan kandang dan area lingkungan tempat kucing bermain, 2) menjauhkan kucing terinfeksi dengan kucing yang sehat, 3) rutin memeriksakan kondisi kesehatan kucing ke dokter hewan (Pets.WebMd.com, 2019).

\section{SIMPULAN}

Kucing di Kota Malang pada kegiatan pengabdian masyarakat menderita scabies sebesar $44 \%$ berdasarkan hasil pemeriksaan sitologi kulit.

\section{- INFORMASI PENULIS}

Penulis untuk Korespondensi

*IAA: indahamaliaamri@gmail.com

Fakultas Kedokteran Hewan, Universitas Brawijaya, Malang, Jawa Timur, INDONESIA

\section{- PUSTAKA ACUAN}

Amanda FZ, Hastutiek P, Sabdoningrum EK, Nunuk DRL, Suprihati E, Eliyani H. 2018. The conformity of diagnostic test between burrow ink test method with skin scrapping method of scabies in rabbit (Lepus domesticus). Journal of Parasite Science 2(1): 29-32

Arlian LG. 1989. Biology, host relations, and epidemiology of Sarcoptes scabiei. Annual review of entomology 34(1): 139 159

Ghubash R. 2006. Parasitic miticidal therapy. Clinical techniques in small animal practice 21(3): 135-144.

Malik R, Stewart KM, Sousa CA, Krockenberger MB, Pope S, Ihrke P, Beatty J, Barrs VR, Walton S. 2006. Crusted scabies (sarcoptic mange) in four cats due to Sarcoptes scabiei infestation. Journal of Feline Medicine and Surgery 8(5):327-39.

Pets.webmd.com 2019. Mange and Scabies in Cats https://pets.webmd.com/cats/cat-mange-scabies\#1(29Juli 2019).

Walton SF, Currie BJ. 2007. Problems in diagnosing scabies, a global disease in human and animal populations. Clinical microbiology reviews 20(2):268-79. 